\title{
Design E-Wallet as a Centralized E-wallet
}

\author{
Devendra Kumar, Upasana Sharma
}

\begin{abstract}
Now days, billions of people are using smart phones all over the world and as the phone gets smarter, the new features gets added that reduces the human efforts in many fields. Smart phone makes the payment of different things such as ordering food, booking a cab, ordering grocery, booking a movie ticket via different mobile applications. These mobile applications work with the support of e-wallets which is recognized as digital wallets. This paper proposes the design of connecting different $e$-wallets present into a single smart phone. The proposed method will make digital payment much less cumbersome.
\end{abstract}

Keywords: UPI, E-Wallet, E-commerce,

\section{INTRODUCTION}

As the technology is changing very fast, we can notice that the current state of technology is totally different from the first generation technology. Earlier, a big room was required to install a computer which could perform some restricted jobs and now everyone is using palmtops, laptops, and smart phones for making the things. It has probably not escaped your attention that smart phone has become an integral part of our lives. It is the key source of our entertainment, bulletin, community lives, and voice message/communication. The smart telephone is attractive even smarter and even additional integral to our daily lives.

Internet makes an easy way for globalization, which brings the e-commerce in the light. In the past, people had to go to market for shopping and the range was limited, but now you can buy anything from your home by using internet connection. E-commerce provides a platform to various merchants where they can sell their product online. It removes the boundaries of the market because the existence of the market on the websites which can be accessed in the presence of internet via desktop devices or smart phones from any corner of the world.

Generally smart phone works on IOS (iPhone OS) or android operating system. These operating systems have different applications to perform specific task that are assigned to them. This paper mainly focuses on the applications used for making payments through smart phone known as e- wallet.

Revised Manuscript Received on December 30, 2019.

* Correspondence Author

Dr.Devendra Kumar, Professor Department of Computer Applications ABES Engineering College, Ghaziabad, (UP), INDIA Email: devendra.arya@gmail.com

Dr.Upasana Sharma, Assistant Professor Department of Information Technology AIIT,Amity University,Noida, (UP), INDIA Email: usharma1@amity.edu

(C) The Authors. Published by Blue Eyes Intelligence Engineering and Sciences Publication (BEIESP). This is an open access article under the CC BY-NC-ND license (http://creativecommons.org/licenses/by-nc-nd/4.0/)
It has been observed that how things changed in the context of shopping and purchasing. Similarly, things get changed from the traditional leather form of wallet to one that resides within or is accessed from our smart phones. As technology has come so far in e-commerce, it opens up different payment methods. Now every e-commerce business has their own e-wallets and some other payment accepting methods that work either through websites or android applications. Therefore, for online payment, we can go for i) add money to e-wallet ii) pay via debit/credit card iii) UPI (Unified Payment Interface) method.

The payment is accepted by e-commerce platform with the help of their digital wallet and these digital wallet dealers sustain relations with online suppliers in the same way they have with credit card companies. These digital wallet vendors earn commission from the seller on all purchase (which involves their wallet as payment mode) or wholesalers pay the vendors a flat fee. In this way, both merchant and customer consume the same products, software and services of a single digital wallet, serving as a center for all transactions between trades and clients. Therefore, it is not necessary for the customer to enter the debit card details in the wallet for each transaction. Instead, send the details of the buyer's business to the customer who is charging the customer. The digital payment system is divided into Individual Consumer and Consumer (C2C) and People to People P2P) objectives. Depending on the style of communication, it is provided that the cost is approximately and the cost of living. Nearby payment is a payment system where payment for an employee is made through short-term communication technology such as nearby Communications. Remote Payment is a system where a user pays through a mobile device and runs a phone payment system at the end; this method works in the same way as debit / credit cards. This includes customers, digital wallet types, banks and credit card companies (PCI). To pay off the debt, the customer signs up to a bank called Acquiring Bank and is obeying the Bank and Digital Wallet mark. The purchasing bank agrees to comply with the rules of the digital marketer, including the PCI database. On the other hand, a customer with a digital wallet shows agreement with their brand and agrees to follow the bank's rules on digital wallet, including PCI, this bank is known as a financial institution as it will put you in a digital wallet. This issuer agrees to abide by the Card Trademark Rules, including PCI data protection standards. Now that the customer pays the merchant with a digital wallet, he goes into the digital wallet information bank. The recipient bank pays the merchant and the credit card receives the information to the company, now the company delivers the information to the bank that issues so that he can charge the customer for the purchase. 


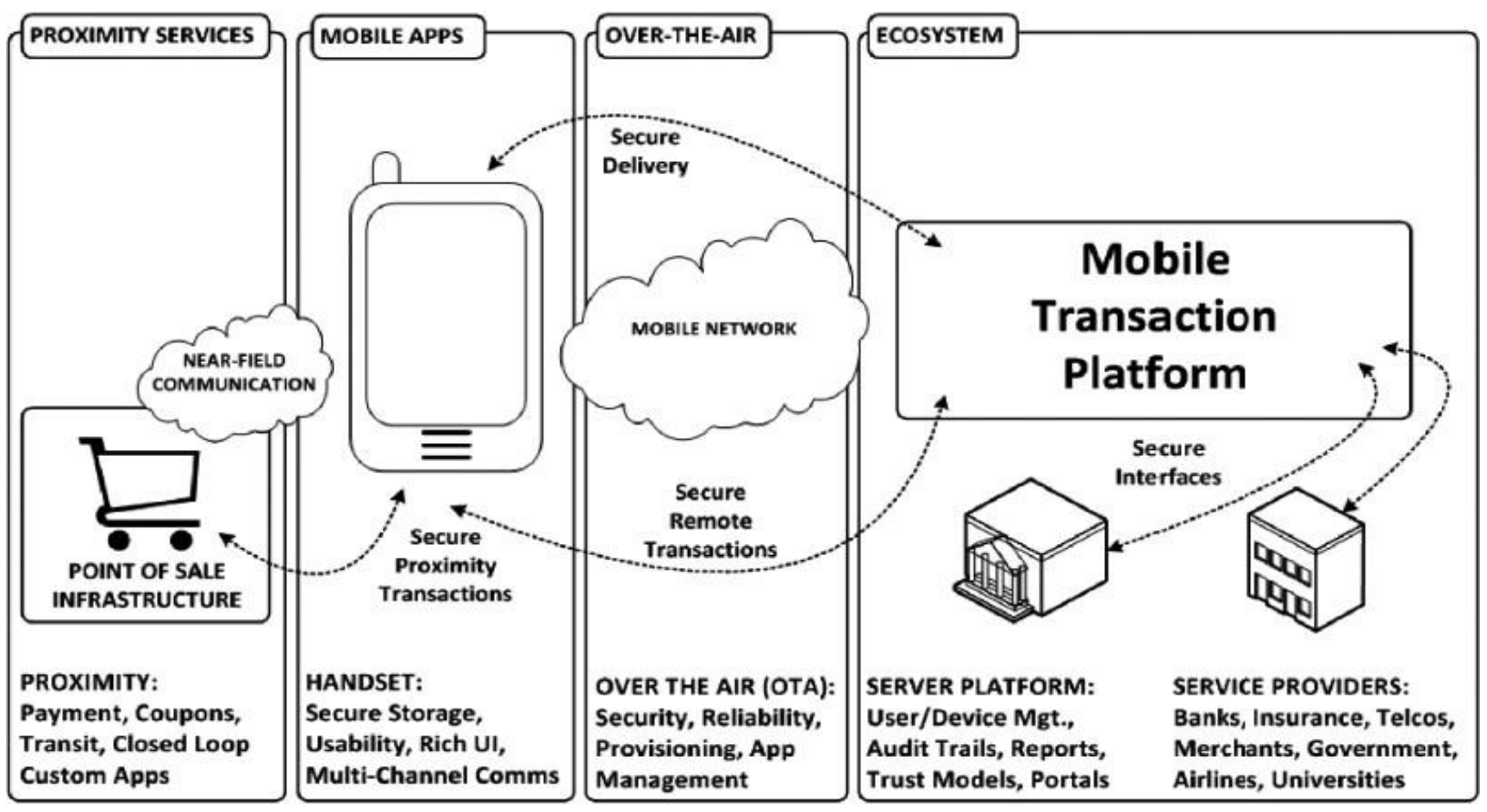

Figure 1: Visual description of how an e-wallet works [2]

\section{LITERATURE SURVEY}

Digital wallets [1] came in the late 1990s with a great deal of hype. In the beginning, these were not widely adopted by public, due to the earliest versions of these wallets. Customer is required to download the software of digital wallet and store it on their desktops to operate. This method was impeded by customers due to downloading problem. The main reason behind this was slow internet connection speed and if the connection breaks down it has to download all over again that leads customers to grow frustrated and abort downloads in middle if they take excessively long time to complete. Another problem was that if the vendor updates its digital wallet software, then customers had to download it all over again. In addition, once the software was downloaded, they were stored on the computer's hard drive, which leads to another problem and that is the customer has to make all purchases from that computer only. But now, we have come so far in technology. M Manikandan and S. Chandramohan [4] have identified that e-wallet is a recent phenomenon. Its adoption will take time, but they are future of cash. The days are not so far when e-wallets will be accepted at every shop and restaurant in India. Ambarish Salodkar and Karan Morey [3] analyzed that e-wallet is a virtual or cashless service used as substitute for physical cash. It represents a new way of buying commodities, without application of physical transaction. It is able to carry out secure transaction that is quick and efficient. On 8 November 2016, Indian prime minister [5] announced demonetization, which thrive an opportunity for digital payment in India. The demonetization resulted in unprecedented growth in digital payment. It is clearly visible from this that people adopt these payment methods on lack of other payment methods. Although educated (beyond matriculation) and internet savvy people were already using digital payment methods. Hem Shweta Rathore stated [8] that people are using digital wallet payment by using smart phones. She also investigated about the various challenges associated with the use of digital wallets. It is easy and comfortable to use digital wallets and beneficial for customers and banks.

S. Manikandan, and J. Mary Jayakodi Stated [9] about the factors that affect the consumer's decision of adopting digital wallets. They found that if security issues are tighten and risk factors are reduced then it will automatically increase in the customers

\section{TYPES OF E-WALLET AND THEIR WORK STYLE}

As per the reserve bank of India, there are three kinds of ewallets in India: closed, semi-closed and open.

Mobile wallets [6] are used for various transactions such as shopping, money transfer, and for purchase of goods and services. However the scope of using them depends upon the type of wallet it is. Basically e-wallet makes the work easy for the user but keeping money in these wallets is not like the money in banks. We get interest on the money which we deposit in the bank but the e-wallet does not pay any interest to the users. They pay interest to the companies operating them. This depends on the type of wallet. The reserve bank of India (RBI) categorizes these E-wallets in three categories that are prevalent in Indian market. 


\section{Treatment of funds in electronic wallets depends on the type of wallet}
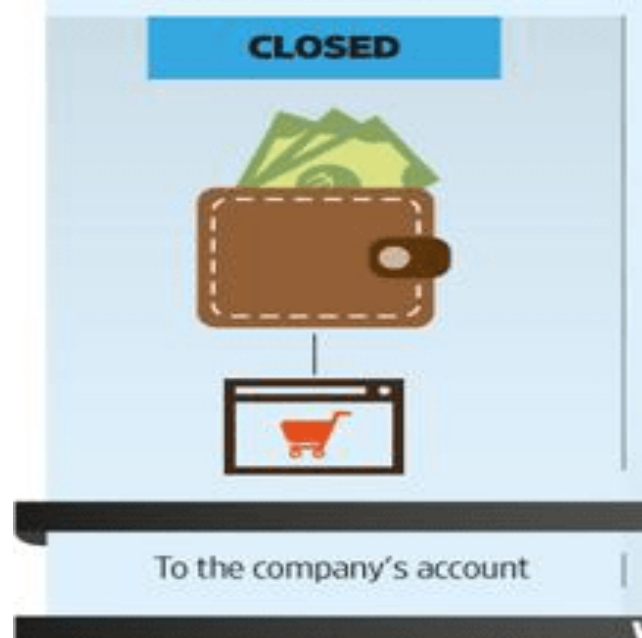

Companies either earn interest on

it, or the money is taken as liability on the books of the company till the

customer uses it to make a purchase

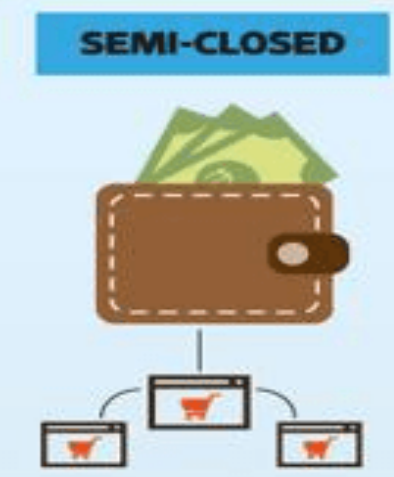

WHERE THE MONEY GOES

To escrow account

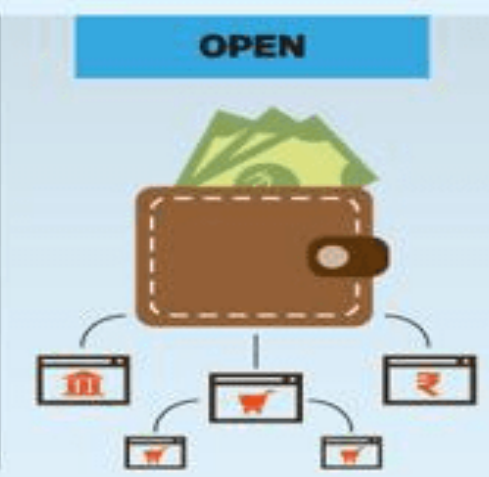

To bank account
WHAT HAPPENS TO THE MONEY

There is either no interest earned, or $4-8 \%$ is earned based on the average balance calculation approved by the central bank
It earns interest, which is

shared between the payment service provider and the bank depending on the agreement

Source: Mint research

Figure 2: Types of e-wallets and its features

Closed e-wallets: Electronic purses are not required for RBI approval. Companies such as Minitra.com, Flipkart.com, Goibibo.com, BookMisho.com These companies issue closed wallets for their users. Problem is, or we can say that the specialty of these wallets is that the money deposited in these wallets can only be used to buy goods or services from companies that have such wallet cases. Closed wallets are pure accounts of a particular website or application where money will be considered if a refund is for cancellation or repayment of a product or service, but as I told you, you can use the money with this particular company. Yes, they do not allow cash withdrawal or redemption. Some companies also earn interest on these deposits.

Semi-Closed e-wallets: It is important to get RBI approval for the issue and implementation of these electronic wallets. This kind of wallet is used to pay merchants. Now these payment bags are a big market. Wallet with Pentium wallet, refrigerator wallet, oxygen etc. fall into the category of halfclosed wallet. These wallets provide their services online and offline, which includes the purchase of goods and services, financial services, payment of fees, premiums, etc. Must be paid to the issuer as part of that payment. These wallets are run by non-banking institutions. Therefore, these agencies are partnering with banks and need to open an escrow account to deposit business money. These institutions also earn interest from the user's deposit under a contract between the bank and the agency.

Open e-wallets: These e-wallets can only be issued by banks and can be used to purchase goods and services, such as a credit card, but are limited to a monetary amount.

With the help of electronic wallets, we can transfer money to any card that receives retailer clips and point of sale
(POS)] and this allows us to cash out on ATMs. Amount of. In fact, this wallet is an advanced version of a half-closed wallet that works with all half-closed wallets combined with several other cash payment and transfer units. M-Pesa [7] is an open wallet operated by Vodafone with the support of ICICI Bank. Axis Bank's electronic wallet card can be used to pay for Visa-approved websites, at least Rs 10 and a maximum of Rs 50,000.

\section{IV.PROBLEM STATEMENT}

As discussed earlier, there are many applications in a smart phone which have their own e- wallets. So when you make any purchase of goods or services through these applications you get various options for making payment. Generally people add money to their e-wallet and pay them. In other words, it is handling separate wallets for different applications which is an overhead. So if we have money in our e- wallet but we cannot use it for other application

Therefore, money in the e-wallet of earlier application will be of no use until you make any payment or transaction through it. In response to this problem, this paper proposes a technique which makes the separate e-wallets of different applications centralized. One can use the money on any platform without any restrictions.

\section{PROPOSED MODEL DIAGRAM}

The proposed model diagram shown in the figure 3. Which is clearly shown that with the help of proposed application/model every e-wallet can share their e-money into another e-wallet and receiving end e-wallet can use the transfer e-money. 


\section{Design E-Wallet as a Centralized E-wallet}
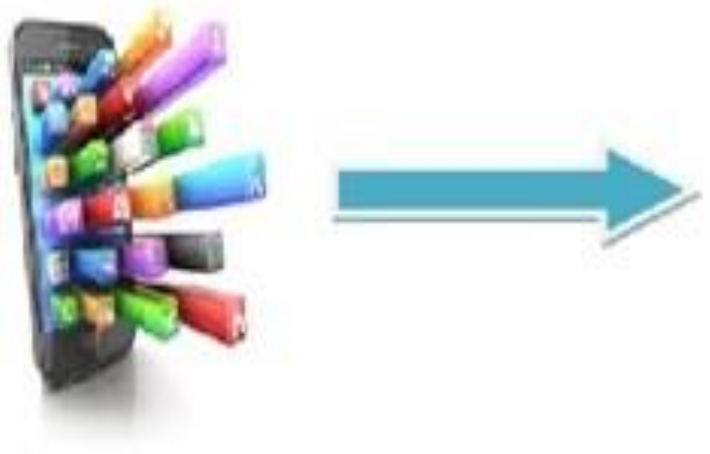

\section{Paytm}

(app that has money in his wallet)

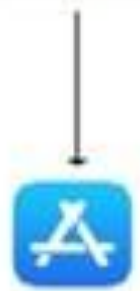

(Centralized e-wallet/proposed application)

pay

(app to which money has to transfer)

Figure 3 Proposed model

\section{ALGORITHM: FLOW OF APPLICATION}

I. A smart phone installed with proposed centralized ewallet application.

II. Register with number or email-id.

III. Login application

IV. Add money to e- wallet.

V. Transfer the money to that application's e-wallet through which a purchase is to be made by entering few details :

a. Select the application to which money has to be transferred.

b. Give the details like register number or id to which money has to be transferred.

c. Enter the amount to be transfer.

VI.Perform the opposite operation i.e. withdrawal of money from different applications and bring it back to the centralized e-wallet application.

a. Select the application from which money has to be withdrawn.

b. Give the details like register number or id from which money has to be withdrawn.

c. Enter the amount you want to withdraw (the amount has to be less than the amount in the later).

VII. Or transfer money directly from one application's wallet to others e-wallet

a. Select the application from which money needs to be transferred.

b. Give the details like register number or id from which money has to be transferred.

c. Select the application to which you want to transfer money.

d. Enter its number or email id on which it works.
VIII. All these steps will be performed by the proposed application which acts as centralized e-wallet. 


\section{BLOCK DIAGRAM OF PROPOSED}

\section{MODEL/APPLICATION}

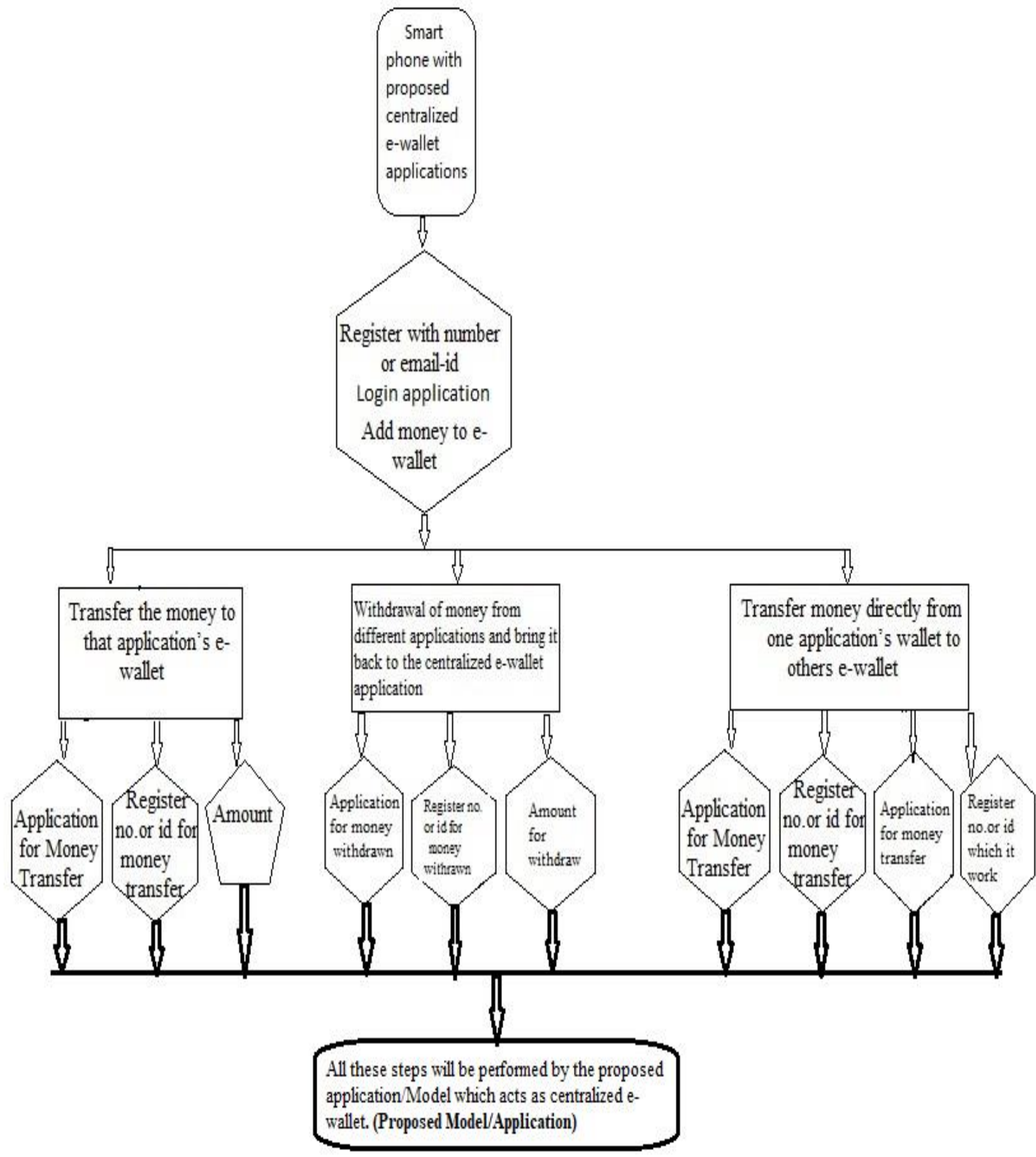

Figure 4 Block diagram of proposed model

\section{RESULT OF PROPOSED MODEL}

There are many applications on a smartphone which have their own e-wallets. So when you make any purchase of goods or services through these applications you get various options for making payment. Generally, people add money to their e-wallet and pay them. In other words, it is handling separate wallets for different applications which is

an overhead. So if we have money in our e-wallet but we cannot use it for other application

Therefore, money in the e-wallet of earlier applications will be of no use until you make any payment or transaction through it. In response to this, we proposed a technique that makes the separate e-wallets of different applications centralized.

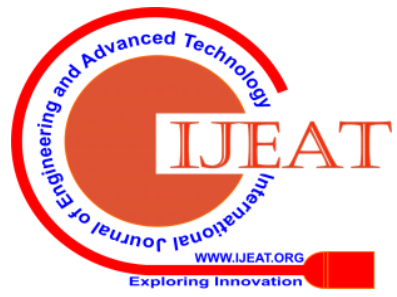




\section{Design E-Wallet as a Centralized E-wallet}

One can use the money on any platform without any restrictions. Different kinds of E-Wallet can share their EWallet money with the help of the proposed or design model. In the past, we can't share the E-Wallet money into other E-wallets. When a user transfers some money with the help of online transfer apps then particular apps give some cashback to a particular use or when users purchase some goods and make a payment through online apps then the user may also receive some cash back in a particular EWallet in the form or E-money. This e-money can't' be transfer or share into another E-wallet or in any account. But with the help of the proposed model/Apps user can easily share the E-Wallet money into another E-Wallet or account.

The proposed application is very useful for all digital transaction and shopping. In this every user or customer can use any e-wallet money in any e-wallet and easily purchase or transfer the e-wallet money anywhere any time 24X7.

\section{CONCLUSIONS}

Taking into account all the anticipated evolutions of technology and strategies introduced by banks or debit/credit card companies, as well as the increase in the number of users, utilizing the electronic payment method inspires to make these payment methods furthermore flexible. This method of making centralized e-wallet applications will be the next step in the process of increasing the flexibility of electronic payment methods. It will bring in plenty of users. It will also remove the overhead of carefully adding the exact amount of money that is required because now an extra amount can be transferred to other application's e-wallet whenever required. Different kinds of E-Wallet can share their E-Wallet money with the help of the proposed or design model. In the past, we can't share the E-Wallet money into other E-wallets. When a user transfers some money with the help of online transfer apps then particular apps give some cashback to a particular use or when user purchase some goods and make a payment through online apps then the user may also receive some cashback in a particular E-Wallet in the form or E-money. This e-money can't' be transfer or share into another E-wallet or in any account. But with the help of proposed model/Apps user can easily share the EWallet money into another E-Wallet or account.

The proposed approach/application is very useful for all the user those who have use digital transaction and online shopping. After this proposed/design application user or customer can use any e-wallet money in any e-wallet and easily purchase or transfer the e-wallet money into any ewallet anywhere.

\section{REFERENCES}

1. Gale Encyclopedia of E-Commerce, 2002, The Gale Group Inc. www.encyclopedia.com/economics/encyclopedias-almanacstranscripts-and-maps/digital-wallet-technology

2. Ngoc Doan CONSUMER ADOPTION IN MOBILE WALLET A Study of Consumers in Finland 2014.

3. Electronic Wallet Ambarish Salodkar, Karan Morey, Prof. Mrs. Monali Shirbhate. International Research Journal of Engineering and Technology (IRJET) Volume: 02 Issue: 09 | Dec-2015.

4. Mobile Wallet- A Virtual Physical Wallet to the customer by M. Manikandan, Dr. S. Chandramohan 2015.

5. Journal of Internet Banking and Commerce, December 2017, vol, 22, no. 3 STUDY OF CONSUMER PERCEPTION OF DIGITAL PAYMENT MODE by SHAMSHER SINGH, RAVISH RA

6. www.feedough.com by Aashish Pahwa UPDATED ON AUG 26, 2017
7. www.feegenie.com/blog/2016/09/05wh at-are-the-types-of-an-ewallet-and-how- many-amount-of-money-can-be-kept-in- those-ewallets by feegenie team.

8. Hem Shweta Rathore, "Adoption Of Digitalwallet By Consumers", Bharati Vidyapeeth's Institute ofMnagement Studies \& Research, Navi Mumba

9. DR.S.Manikandan, and J.Mary Jayakodi. (2017). "AN EMPRICAL STUDYON CONSUMERS ADOPTION OF MOBILE WALLET WITH SPECIAL REFERENCE TOCHENNAI CITY.” International Journal of Research - Granthaalayah, 5(5), 107-115.

10. Images downloaded fromgoogle search images and flippa blog i.e blog.flippa.com/verifying-app- performance/JULY3,2015 MEGAN IINTON PAYTM

11. https://www.google.co.in/url?sa=i\&source=images\&cd=\&ved=2ahU KEwir4K3_q5jcAhVBb30KHQpyDTgQjRx6BAgBEAU\&url=https\% 3A\%2F\%2Fplay.google.com\%2Fstore\%2Fapps\%2Fdetails\%3Fid\%3 Dnet.one97.paytm\%26hl\%3Den_US\&psig=AOvVaw1UvgHGlOIgE7 6nak1PXw\&ust=1531442873373884

12. https://www.google.co.in/search?q=amazon+pay\&source=lnms\&tbm $=$ isch\&sa $=$ X\&ved $=0$ ahUKEwiJt5z5NzbAhXaV30KHVLCBAwQ_A UICygC\&biw=1536\&bih=683\#imgrc=aQkbS5 lxYLmKiM

13. DivyaniYadav, D. Gupta, D. Singh, D. Kumar and U. Sharma, "Vulnerabilities and Security of Web Applications," 2018 4th International Conference on Computing Communication and Automation (ICCCA), Greater Noida, India, 2018, pp. 1-5. doi: 10.1109/CCAA.2018.8777558

14. Kumar, Devendra, and Mr Gajendra Singh. "Analytical Study of Structure of Models and Techniques of Privacy Preserving Data Mining. International Journal of Advances Research in Computer Science (IJARCS) www. ijictm.org URL: http://www.ijictm.org/admin/html/mail/attach/2013-07-30-08-4429.pdf

15. K.Suma vally, Dr. K.Hema Divya A study on Digital payments in Indiawith perspective of consumers adoption International Journal of Pure and Applied Mathematics Volume 118 No. 242018 http://www.acadpubl.eu/hub/

16. T.Praiseye,2Dr.Florence John Madras Christian College A STUDY ON CONSUMER PREFERENCE TOWARDS MOBILE WALLET 2018 IJRARSeptember2018, Volume 5, Issue 3 www.ijrar.org (EISSN 2348-1269, P-ISSN 2349-5138)

17. Madhu Chauhan, Isha Shingari Future of e-Wallets: A Perspective FromUnder Graduates' International Journals of Advanced Research in Computer Science and Software EngineeringISSN: 2277-128X (Volume-7, Issue-8) August 2017

18. https://www.ijitee.org/wpcontent/uploads/papers/v8i12/L37711081219 .pdf

19. Madhusudan Chandok, Devendra Kumar, Upasana Sharma, Sandeep Mathur D-Crush: A Stronger Approach Towards Web Security", Dec.2017, Volume No.-3, issue - 2 in International Journal of Software Computing and Testing,eISSN-2456-2351

20. https://www.semanticscholar.org/paper/Vulnerabilities-and-Securityof-Web-Applications-DivyaniYadav

Gupta/034a2766160ea1e17e53335f14ba4b7802b0be72

21. https://www.ipemgzb.ac.in/ipem-Journal/Computer-ScienceJournal.pdf

22. http://computers.journalspub.info/index.php?journal=JSCT\&page=arti cle\&op=view\&path $\% 5 B \% 5 \mathrm{D}=302$

23. http://www.ijictm.org/admin/html/mail/attach/2013-07-30-08-4429.pdf

24. http://www.rjset.com/abstractview/5283

\section{AUTHORS FROFILE}

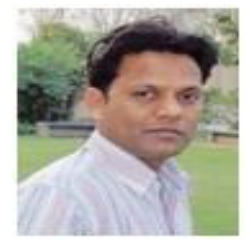

Devendra Kumar, has received the Ph.D. degree in CSE, M.Tech in CSE, MCA and B.Sc in PCM. He works as a Professor in the Department of Computer Applications at ABES Engineering College, Ghaziabad, INDIA. He has more than 15 years of Teaching and research Experience. He is member of Computer Society of India, International Association of Engineers, International Association of Computer Science and Information Technology, International Economics Development Research Center and The Institution of Engineers \& Technology. He is reviewer member of Editorial board of Splendid Journals, International Journal of Computer Science and Programming Language, International Journal of Information Security and Software Engineering and International Journal of Mobile Computing Devices. 
His areas of interest are Data Mining, Software Engineering, IOT, Information /Database/ System/Network Security. He has published so many papers in the field of Data Mini, ERP, Security, IOT and AI.

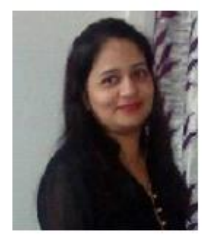

Upasana Sharma, has received Ph.D. Degree at Amity University. She is an MCA from UPTU, Lucknow, India and gets B.Sc. (PCM) from Chaudhary Charan Singh University, Meerut, India. She works as an assistant professor at Amity Institute of Information Technology, Amity University. She has 15 years of teaching experience. Her research interest is in data mining, AI, Social Media etc 